\title{
Seronegative pauciarticular arthritis and HLA B27
}

\author{
C. J. EASTMOND ${ }^{1}$, S. M. RAJAH ${ }^{2}$, D. TOVEY ${ }^{2}$, AND V. WRIGHT \\ From the ${ }^{1}$ Rheumatism Research Unit, University Department of Medicine, General Infirmary at Leeds, and \\ the ${ }^{2}$ Regional Blood Transfusion Laboratory, Bridle Path, Leeds
}

SUMMARY Twenty-six patients with a pauciarticular arthritis have been studied clinically, radiologically and with histocompatibility typing. An increased frequency of HLA B27 was found $\left(\mathrm{p}=1.87 \times 10^{-12}\right)$. Low back and buttock pain, Achilles tendinitis and dactylitis of the toes were more frequent in HLA-B27 positive patients. It is suggested that histocompatibility testing may be of some value in diagnosis and in the investigation of the possible 'reactive' nature of this type of arthritis.

Since the demonstration of an increased frequency of HLA B27 in patients with ankylosing spondylitis ${ }^{12}$ other forms of seronegative arthritis ${ }^{3}$ have been studied and found to have a high frequency of HLA B27. ${ }^{4-7}$ The arthritis of ankylosing spondylitis and the other inflammatory seronegative arthritides is known to have certain characteristic features. These include the predominant involvement of the weight bearing joints with an asymmetrical distribution, heel pain sometimes with the formation of a bony calcaneal spur, tendinitis, particularly of the Achilles tendon, and dactylitis.

In a recent retrospective study of 151 patients with a monoarticular onset of their arthritis, Fletcher and $\mathrm{Scott}^{8}$ demonstrated a varied final diagnosis. In 6 patients it was possible to make a diagnosis of one of the seronegative spondarthritides, but 49 patients remained without a final diagnosis. Arnett et al. ${ }^{9}$ have described an incomplete form of Reiter's syndrome in 13 patients, 9 of whom gave a history of recent venereal exposure or dysenteric illness. One patient had mucocutaneous lesions typical of Reiter's syndrome but no urethritis. Twelve of the patients were HLA B27 positive. Joliat et al. ${ }^{10}$ described 18 patients predominantly female with a seronegative inflammatory arthritis. Apart from heel pain and Achilles tendinitis they were unable to demonstrate any differences between the patients who were HLA B27 positive and those who were negative. De Ceulaer et al. ${ }^{11}$ described 9 HLA B27 positive patients without sacroiliitis who had dactylitis of the toes. Out of a group of 71 HLA

Accepted for publication.

Correspondence to Professor V. Wright, Rheumatism Research Unit, School of Medicine, 36 Clarendon Road, Leeds LS2 9PJ.
B27 positive patients Keat and Barnes ${ }^{12}$ described 8 patients with a monoarthritis of the lower limb joints, four of whom did not have radiological sacroiliitis and followed a relatively benign course. In their survey Lawrence and Bennett ${ }^{13}$ saw 84 patients who gave a past history of polyarthritis, but in many no precise diagnosis was possible. It is of interest to note that the course of the polyarthritis was usually benign and that none had radiological sacroiliitis.

The present study was set up to determine the frequency of HLA B27 in patients with this pattern of arthritis and any particular clinical features that may be associated with this tissue antigen. It was also hoped to be able to evaluate the possible diagnostic help provided by tissue typing in this particular form of arthritis.

\section{Patients and methods}

The patients were seen personally by one of us (C.J.E.) in rheumatology clinics. The pattern of arthritis at onset and since was noted, and patients were specifically questioned concerning low back pain, symptoms of urethritis, conjunctivitis, uveitis, psoriasis, and chronic inflammatory bowel disease. A full clinical examination was performed. In the absence of symptoms of urethritis no special genitourinary investigations were performed. All patients had a sensitised sheep cell test performed and were included only if this was negative. An anteroposterior radiograph of the pelvis was taken, and the patients with bilateral grade 2 or greater radiological sacroiliitis were excluded.

All patients and 229 blood donor controls were tested for 25 histocompatibility antigens. 


\section{Results}

A total of 26 patients (20 male) satisfied the criteria for inclusion in this study. The mean age of onset of the arthritis was $29 \cdot 3$ years (range 9-64 years) with the mode in the first half of the third decade (Fig. 1). Most patients had 2 or fewer joints involved (Fig. 2). The most commonly affected joint was the knee joint in $22(84.6 \%)$ patients. Other frequently involved joints and sites were the ankles and the low back or buttocks (Fig. 3).

Six patients had extra-articular symptoms associated with seronegative inflammatory arthritis. One male had a preceding diarrhoeal illness, and a further male patient had a constitutional disturbance with a succeeding diarrhoea. No faecal organisms could be detected, and serology for Salmonella typhi and $S$. paratyphi and Yersinia enterocolitica were negative in both. One further male developed Reiter's syndrome 2 years after his inflammatory arthritis had resolved. Another male developed uveitis 1 year after the first episode of arthritis. One female had had uveitis 2 years previously, and a further female developed a rash on the lower legs without features of psoriasis or erythema nodosum.

\section{OLIGOARTHRITIS NO Of PATIENTS}

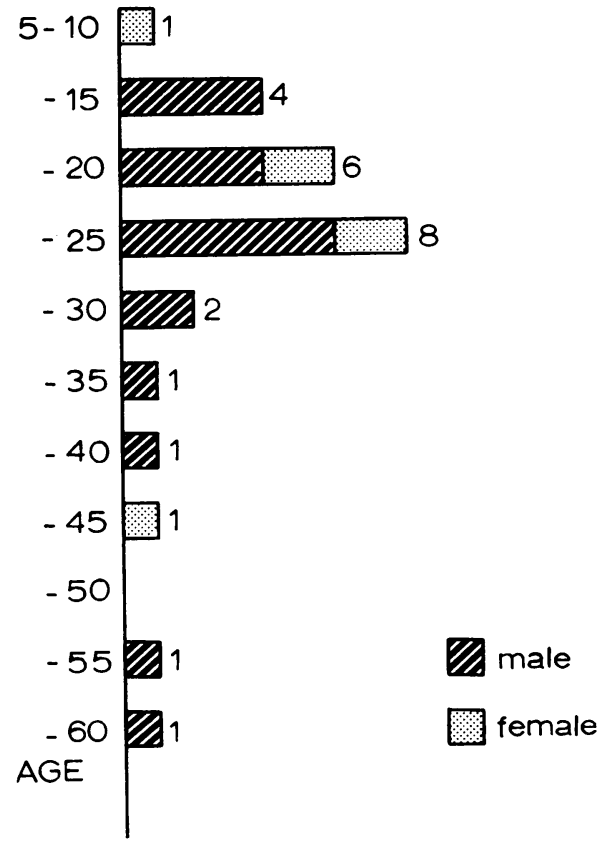

Fig. 1 Histogram of age of onset of arthritis.

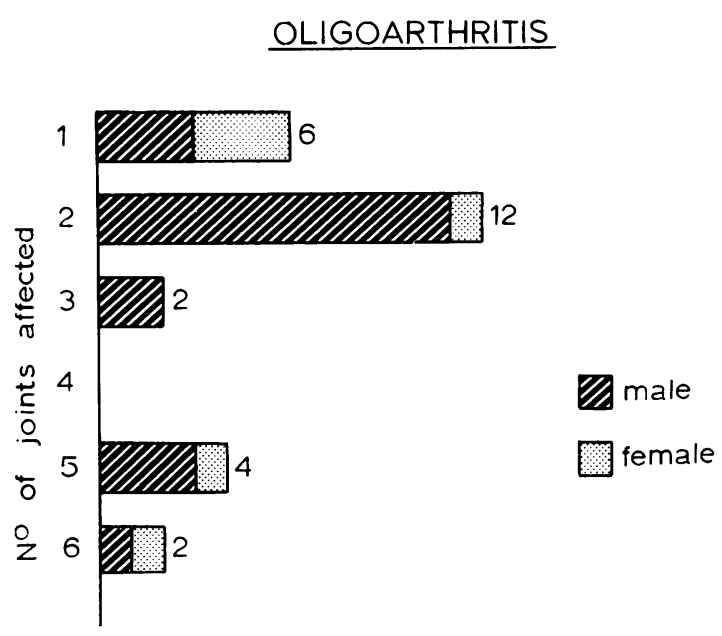

Fig. 2 Graph of number of joints involved by arthritis.

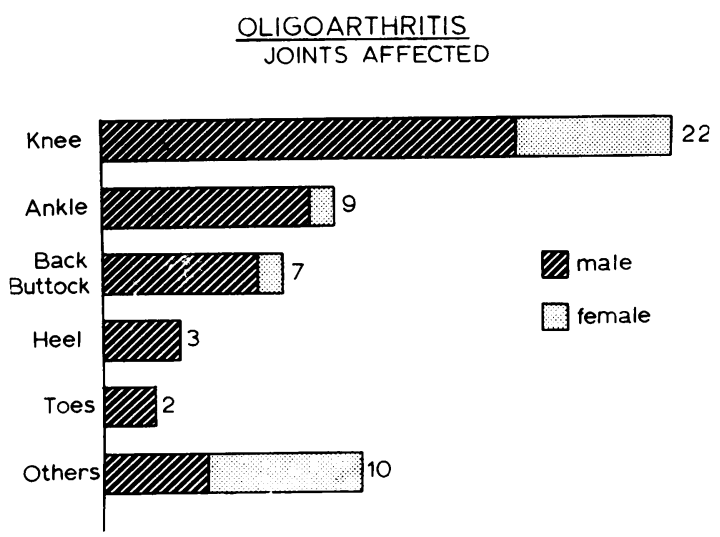

Fig. 3 Histogram of frequency of individual joint involvement.

Two males had a family history of ankylosing spondylitis; one had a father affected and the other a father and a paternal uncle. One female patient gave a family history of psoriasis in a paternal uncle. In the remaining 17 patients the extra-articular features and family history were unremarkable.

The pelvic $x$-rays were all subsequently read at 1 sitting. Two patients were considered to have minimal abnormality of the sacroiliac joints. One male patient had a grade 2 unilateral sacroiliitis and 1 female a grade 1 unilateral sacroiliitis.

Eighteen patients $(69 \cdot 2 \%)$ were HLA B27 positive compared with $27(11.8 \%)$ of 229 controls giving $\chi_{\mathrm{c}}^{2}=49 \cdot 12 ; \mathrm{p}=1.87 \times 10^{-12}$. No other histocompatibility antigen was present in a significantly increased frequency (Table 1). Fourteen 
( $70 \%$ ) of the 20 males were HLA B27 positive, and $4(67 \%)$ of the 6 female patients were HLA B27 positive.

Comparison of HLA B27 positive and negative patients (Table 2) indicates a similar sex ratio and mean age of onset. All 6 patients having extraarticular features associated with inflammatory seronegative arthritis were HLA B27 positive. This antigen was also present in the 3 patients who gave a family history of ankylosing spondylitis or psoriasis. The 2 boys whose fathers had ankylosing spondylitis had inherited the same B27-containing haplotype as their fathers. The number of joints affected was similar in both groups of patients (Table 3). The knees were equally commonly affected in the 2 groups. The HLA B27 positive patients had more low back or buttock symptoms, heel symptoms, or

Table 1 Histocompatibility antigen frequencies in 26 patients with pauciarticular seronegative arthritis and controls

\begin{tabular}{|c|c|c|c|c|}
\hline \multirow{2}{*}{$\begin{array}{l}\text { HLA } \\
\text { antigen }\end{array}$} & \multicolumn{2}{|c|}{ Patients (26) } & \multicolumn{2}{|c|}{ Controls (229) } \\
\hline & $\begin{array}{l}\text { Number } \\
\text { positive }\end{array}$ & $\begin{array}{l}\text { Percent } \\
\text { positive }\end{array}$ & $\begin{array}{l}\text { Number } \\
\text { positive }\end{array}$ & $\begin{array}{l}\text { Percent } \\
\text { positive }\end{array}$ \\
\hline $\begin{array}{l}\text { A1 } \\
\text { A2 } \\
\text { A3 } \\
\text { A9 } \\
\text { A10 } \\
\text { A11 } \\
\text { A28 } \\
\text { A29 } \\
\text { AW19 } \\
\text { A blank }\end{array}$ & $\begin{array}{r}7 \\
16 \\
4 \\
5 \\
3 \\
4 \\
2 \\
0 \\
2 \\
9\end{array}$ & $\begin{array}{r}269 \\
61 \cdot 5 \\
15 \cdot 4 \\
19 \cdot 2 \\
11 \cdot 5 \\
15 \cdot 4 \\
7 \cdot 7 \\
7 \cdot 7 \\
346\end{array}$ & $\begin{array}{r}75 \\
106 \\
69 \\
43 \\
16 \\
32 \\
20 \\
18 \\
23 \\
20\end{array}$ & $\begin{array}{r}32 \cdot 8 \\
46 \cdot 3 \\
30 \cdot 1 \\
18 \cdot 8 \\
7 \cdot 0 \\
14 \cdot 0 \\
8 \cdot 7 \\
7 \cdot 9 \\
10 \cdot 0 \\
8 \cdot 9\end{array}$ \\
\hline B5 & 0 & - & 17 & $7 \cdot 4$ \\
\hline B7 & 5 & $19 \cdot 2$ & 78 & $34 \cdot 1$ \\
\hline 8 & 7 & 269 & 50 & $21 \cdot 8$ \\
\hline B12 & 6 & $23 \cdot 1$ & 65 & $28 \cdot 4$ \\
\hline B13 & 0 & - & 6 & $2 \cdot 6$ \\
\hline B14 & 2 & $7 \cdot 7$ & 22 & $9 \cdot 6$ \\
\hline B15 & 1 & $3 \cdot 8$ & 35 & $15 \cdot 3$ \\
\hline BW16 & & - & 9 & $3 \cdot 9$ \\
\hline B1 & 0 & - & 29 & $12 \cdot 7$ \\
\hline B18 & 1 & $3 \cdot 8$ & 16 & 7.0 \\
\hline BW21 & 0 & - & 8 & $3 \cdot 5$ \\
\hline BW22 & 0 & - & 9 & $4 \cdot 0$ \\
\hline B27 & 18 & $69 \cdot 2$ & 27 & $11 \cdot 8$ \\
\hline BW35 & 3 & $11 \cdot 5$ & 22 & 9.6 \\
\hline BW37 & 0 & - & 4 & $1 \cdot 8$ \\
\hline BW40 & 2 & $7 \cdot 7$ & 32 & $14 \cdot 0$ \\
\hline B Blank & 7 & $26 \cdot 9$ & 5 & $2 \cdot 0$ \\
\hline
\end{tabular}

Table 2 Sex ratio and age of onset of arthritis with regard to $H L A B 27$ positivity

\begin{tabular}{llll}
\hline & & $\begin{array}{l}\text { HLA B27- } \\
\text { positive }\end{array}$ & $\begin{array}{l}\text { HLA B27- } \\
\text { negative }\end{array}$ \\
\hline Sex ratio M:F & & $14:$ & $6: 2$ \\
\hline Mean (range) & Males & $24(11-56)$ & $30 \cdot 8(19-64)$ \\
$\begin{array}{l}\text { Age of onset } \\
\text { (years) }\end{array}$ & Females & $21 \cdot 8(9-36)$ & $20 \cdot 5(20-21)$ \\
\hline
\end{tabular}

Table 3 Number of joints affected with regard to HLA B27 positivity

\begin{tabular}{lll}
\hline $\begin{array}{l}\text { Number of joints } \\
\text { affected }\end{array}$ & $\begin{array}{c}\text { HLA B27-positive } \\
(18)\end{array}$ & $\begin{array}{c}\text { HLA B27-negative } \\
(8)\end{array}$ \\
\hline 1 & 3 & 3 \\
2 & 9 & 3 \\
3 & 2 & 0 \\
4 & 0 & 0 \\
5 & 2 & 2 \\
6 & 2 & 0 \\
\hline
\end{tabular}

Table 4 Sites of arthritis with regard to $H L A$ B27 positivity

\begin{tabular}{lll}
\hline Joints affected & $\begin{array}{l}\text { HLA B27-positive } \\
(18)\end{array}$ & $\begin{array}{l}\text { HLA B27-negative } \\
(8)\end{array}$ \\
\hline Knee & 15 & 7 \\
Ankle & 5 & 4 \\
Back/buttock & 6 & \\
Heel & 3 & 0 \\
Toes & 2 & 0 \\
Others & 9 & 1 \\
\hline
\end{tabular}

Table 5 Outcome of arthritis with regard to HLA B27

\begin{tabular}{llll}
\hline Outcome & $\begin{array}{l}\text { HLA B27 } \\
\text { positive (18) }\end{array}$ & $\begin{array}{l}\text { HLA B27 } \\
\text { negative (8) }\end{array}$ & $\begin{array}{l}\text { Total } \\
(26)\end{array}$ \\
\hline Resolved & 6 & 4 & 10 \\
Recurred & 6 & 3 & 9 \\
Persistent & 1 & 0 & 1 \\
$\begin{array}{l}\text { Follow-up } \\
\text { insufficient }\end{array}$ & 5 & 1 & 6 \\
\hline
\end{tabular}

involvement by dactylitis of the toes than the HLA B27 negative patients. The HLA B27 negative patients had slightly more involvement of the ankles than the HLA B27 positive patients. The other joints were so infrequently affected as to make comparisons impracticable (Table 4).

In 19 patients the episode of arthritis was known to have resolved without residua, but in 9 of these recurrence had subsequently occurred after periods of between 6 months and 13 years. Only 1 female patient had persistently active arthritis. Follow-up was insufficient (less than 6 months) to determine the outcome in 6 patients. The outcome was not related to histocompatibility type (Table 5 ).

\section{Discussion}

The pattern of arthritis and male predominance in this group of 26 patients is very similar to that seen in patients with juvenile pauciarticular arthritis who later develop ankylosing spondylitis and in patients with Reiter's syndrome. Although the majority of patients had an age of onset in the third decade, 5 patients would satisfy the criteria for juvenile 
arthritis. It is known that this group have an increased frequency of HLA B27 and are at risk for the development of subsequent ankylosing spondylitis. The present study demonstrates that an identical arthritis, also with an increased frequency of HLA B27, may occur in adults who do not have the clinical or radiological stigmata of any other seronegative spondarthritis. The present study, however, is unable to indicate what proportion of these patients are at risk for the subsequent development of ankylosing spondylitis, since the follow-up period in many has been too short. It might, however, be expected that at least some will develop ankylosing spondylitis, though it should be noted that 3 patients are already aged 45 years or older, making future development of spinal disease relatively unlikely.

It is of interest to note that 6 patients had extraarticular features associated with seronegative inflammatory arthritis at some time, but in only the 2 patients with diarrhoea were these directly related to the episode of arthritis under review. With the development of such symptoms it may be possible subsequently to make a more definitive diagnosis. The other patients, however, having no such features, have an uncertain diagnosis based entirely on the pattern of the arthritis. It is probable that in this small highly selected group of patients histocompatibility typing for diagnostic purposes may have some value, with possible therapeutic and prognostic implications.

The underlying cause of this arthritis is unknown. The clinical pattern and association with HLA B27 suggests a reactive arthritis. Clinically only 2 patients had overt evidence of infection directly related to the episode of arthritis and in both of them bacteriological and serological investigations for known bacterial precipitants were lacking. Patients without symptoms were not all routinely investigated in this way. It is possible that some of these may represent examples of reactive arthritis due to occult Yersinia enterocolitica infection ${ }^{14}$ or Salmonella typhimurium. The recent findings of an increased carriage rate of faecal Klebsiella aerogenes in HLA B27 positive patients with ankylosing spondylitis and active peripheral arthritis ${ }^{15}$ raises the possibility of this organism having a pathogenic role in HLA B27 positive patients with peripheral arthritis alone. Improved identification of this group of patients by histocompatibility typing should assist the further investigation of these possibilities.

\section{Conclusions}

(1) Histocompatibility typing is probably of some diagnostic value in the investigation of adult and juvenile patients with seronegative pauciarticular disease, when other diagnostic features are lacking. (2) This type of arthritis is usually self-limiting but recurrence after a variable interval may occur. (3) Symptoms related to the enthesis and spine are more common in HLA B27 positive patients. (4) The pattern of arthritis and its association with HLA B27 suggests the possibility of a 'reactive' aetiology.

\section{References}

1 Brewerton D A, Caffrey M, Hart F D, James D C O, Nicholls A, Sturrock R D. Ankylosing spondylitis and HL-A 27. Lancet 1973; i: 904-7.

2 Schlosstein L, Terasaki P I, Bluestone R, Pearson C M. High association of an HL-A antigen, W 27, with ankylosing spondylitis. $N$ Engl J Med 1973 ; 288: 704-6.

3 Wright V, Moll J M H. Seronegative Polyarthritis. Amsterdam: North-Holland, 1976.

4 Brewerton D A, Caffrey M, Nicholls A, Walters D, Oates J K, James D C O. Reiter's disease and HL-A 27. Lancet 1973; ii: 996-8.

5 Brewerton D A, Caffrey M, Nicholls A, Walters D, James D C O. HL-A 27 and arthropathies associated with ulcerative colitis and psoriasis. Lancet 1974; i: 956-958.

6 Brewerton D A. HL-A27 and acute anterior uveitis. Ann Rheum Dis 1975; 34 (Suppl): 33-5.

7 Edmonds J, Morris R I, Metzger A L, et al. Follow-up study of juvenile chronic polyarthritis with particular reference to histocompatibility antigen W.27. Ann Rheum Dis 1974; 33: 289-92.

8 Fletcher M R, Scott J T. Chronic monarticular synovitis. Diagnostic and prognostic features. Ann Rheum Dis 1975; 34: 171-6.

9 Arnett F C, McClusky O E, Schacter B Z, Lordon R E. Incomplete Reiter's syndrome; discriminating features and HL-AW27 in diagnosis. Ann Intern Med 1976; 84: 8-12.

10 Joliat G, Ferro A, Jeannet M, Ott H. HLA-B27 antigen in diagnosis of atypical seronegative inflammatory arthropathy. Ann Rheum Dis 1976; 35: 531-3.

11 De Ceulaer K, Van der Linden J M J P, Cats A. (1977). "Sausage-like" toes (dactylitis) and HLA-B27.J Rheumatol 1977; 4 (Suppl 3): 66-9.

12 Keat A C, Barnes R M R. HL-A 27-associated arthritis. Rheumatol Rehabil 1976; 15: 87-91.

13 Lawrence J S, Bennett P H. Benign polyarthritis. Ann Rheum Dis 1960; 19: 20-9.

14 Scott J T, Mair N S. Yersinia arthritis. Br Med J 1979; i: 1251.

15 Eastmond C J, Wilshaw H E, Burgess S E, Shinebaum $R$, Cooke E M, Wright $V$. The frequency of faecal Klebsiella aerogenes in patients with ankylosing spondylitis and controls with respect to individual features of the disease. Ann Rheum Dis in press. 